\title{
Combined Effects of Radiofrequency Electromagnetic Fields and X-Ray in Renal Tissue and Function
}

This article was published in the following Dove Press journal: Research and Reports in Urology

Sajad Borzoueisileh ${ }^{1,2}$

Ali Shabestani Monfared (iD) ${ }^{3}$

Hossein Ghorbani ${ }^{4}$

SMJ Mortazavi $\mathbb{D}^{5}$

Ebrahim Zabihi ${ }^{\prime}{ }^{\prime}$

Mehdi Pouramir'

Mohsen Shafiee ${ }^{6}$

Fatemeh Niksirat ${ }^{7}{ }^{7}$

'Cellular and Molecular Biology Research Center, Health Research Institute, Babol University of Medical Sciences, Babol, Iran; ${ }^{2}$ Student Research Committee, Babol University of Medical Sciences, Babol, Iran; ${ }^{3}$ Cancer Research Center, Health Research Institute, Babol University of Medical Sciences, Babol, Iran; ${ }^{4}$ Pathology Department, Babol University of Medical Sciences, Babol, Iran; ${ }^{5}$ Department of Medical Physics, School of Medicine, Shiraz University of Medical Sciences, Shiraz, Iran; ${ }^{6}$ Cellular and Molecular Research Center, Yasuj University of Medical Sciences, Yasuj, Iran; ${ }^{7}$ Department of Medical Physics Radiobiology and Radiation Protection, School of Medicine, Babol University of Medical Sciences, Babol, Iran
Correspondence: Ali Shabestani Monfared

Cancer Research Center, Babol

University of Medical Sciences,

Ganjafrooz St., Babol, Iran

Tel +989I I I 230475

Fax +98 II 35289733

Email monfared_ali@yahoo.com
Purpose: Biochemical and histopathological properties of renal tissues were reported to be affected by both radiofrequency electromagnetic fields (RF-EMF) and ionizing radiation. The radiation-induced changes in the kidney, including the serum levels of blood urea nitrogen (BUN) and creatinine ( $\mathrm{Cr}$ ), could lead to adverse health outcomes such as chronic kidney disease. These complications signify the importance of the research in this field. Thus, in this study, the effects of ionizing and non-ionizing radiations, as well as their combination, were assessed by evaluating the alteration in BUN, Cr, and histopathological changes in kidney tissue. Materials and Methods: Ninety-six male Wistar rats were randomly divided into six groups and were exposed to either $900 / 1800 \mathrm{MHz}$ (mobile phone) or $2.4 \mathrm{GHz}$ RF-EMF (WiFi) radiation for 14 days, $8 \mathrm{~Gy}$ x-ray, or their combination. Sera were collected from $2 \mathrm{~mL}$ of rat blood, then BUN and $\mathrm{Cr}$ levels were determined. Also, renal samples were stained with hematoxylin and eosin and evaluated histopathologically.

Results: Both BUN and Cr levels raised non-significantly after exposure to 8 Gy x-rays. Moreover, all measurements in the samples of x-ray groups were in borderline or higher than normal values. The BUN levels of control, Wi-Fi, x-ray, and $\mathrm{Wi}-\mathrm{Fi}+\mathrm{x}-$ ray groups were not significantly different. However, Cr levels in the Wi-Fi group were significantly higher than those of the controls, and BUN to Cr ratio levels were significantly lower than those of the controls. Also, tubular atrophy and vessel wall thickening were associated with these exposures.

Conclusion: Exposure to $900 / 1800 \mathrm{MHz}, 2400 \mathrm{MHz}$ EMF can alter the kidney function. However, pre-exposure to $900 / 1800 \mathrm{MHz}$ EMF could modulate the acute adverse effects of lethal $\mathrm{x}$-ray dose, which addresses the adaptive response in the kidney.

Keywords: EMF, RF, kidney, mobile phone radiation, Wi-Fi radiation

\section{Introduction}

The electromagnetic spectrum consists of a range of frequencies and wavelengths that define their biological effects. One side of this spectrum is the ionizing radiations, and the other side is non-ionizing radiations. ${ }^{1}$ While the nature of both ionizing and nonionizing radiations are similar, but, they have different effects on living tissues. Ionizing radiations, including $\mathrm{x}$ and gamma rays, may have direct and indirect effects, which eventually lead to chemical changes in the tissue molecules. ${ }^{2,3}$ HighFrequency electromagnetic fields (EMF) have thermal and non-thermal effects, ${ }^{4}$ and this type of radiation is an integral part of today's life, especially in the communications industry. 
Mobile phones in different generations use different bandwidths from 800 to $3000 \mathrm{MHz}$, and Wi-Fi routers are using 2.4 GHz EMF, commonly. ${ }^{5,6}$ The newer generations of communication vehicles may employ different frequencies. ${ }^{6}$ However, literature indicating that the biological response to different frequencies and other physical properties, including specific absorption rate (SAR), could be dissimilar ${ }^{7}$ that address the needs to continue the scientific research to monitor their biological effects. Furthermore, the exact mechanisms of EMF effects are not precise yet. Also, the increasing use of ionizing and non-ionizing radiations in daily life in fields such as diagnosis, and treatment of different diseases may alter the renal tissue and function observed as changes in serum levels of blood urea nitrogen (BUN) and creatinine $(\mathrm{Cr})$. Eventually, these changes can lead to adverse health outcomes, such as chronic kidney disease. Given this consideration, we should evaluate the EMF effects and their interactions with other agents in different body organs.

Different physical, chemical, and biological parameters could modulate the irradiation effect. One of the critical parameters is the type of cells or tissue. Biochemical and histopathological properties of renal tissue were reported to be affected by EMF and ionizing radiation. ${ }^{8,9}$ Tubular necrosis, glomerular atypia, tubular cast formation, and vascular congestion was reported to be observed in the renal tissue due to irradiation. ${ }^{10}$ Also, oxidative damage ${ }^{11}$ and the difference in the BUN and $\mathrm{Cr}$ are some effects of radiation in the renal tissue. $^{12}$

The radiation-induced changes in the kidney function, including a rise in serum levels of BUN and $\mathrm{Cr}$, could lead to subsequent difficulties such as chronic kidney disease. ${ }^{13}$ These complications signify the importance of the research in this field. Then, in this study, the effects of ionizing, nonionizing radiations, and their combination were assessed by evaluating the alteration in $\mathrm{BUN}, \mathrm{Cr}, \mathrm{BUN} / \mathrm{Cr}$ ratio and also, histopathological changes in the kidney tissue.

\section{Materials and Methods Study Design and Irradiations}

In this case-control study, we have evaluated the effect of 900/ $1800 \mathrm{MHz}$ EMF of cell phone (Nokia 1280, India) radiation and $2.4 \mathrm{GHz}$ EMF radiation of commercial Wi-Fi router (D-Link DSL-2740U ADSL2 Plus Wireless N300 Modem Router, China) on 96 rats in six groups. We had four control groups including a sham control (control group), a positive x-ray control (RT group) that received 8 Gy x-ray, positive mobile phone control (mobile group) that received 12 hours a day for 14 days 900/1800 MHz EMF, and Wi-Fi control (WiFi group), which received 12 hours a day for 14 days 2400 $\mathrm{MHz}$ EMF radiations. Also, we had a mobile phone+ $\mathrm{x}$-ray group (mobile+ RT group) exposed to 12 hours a day for 14 days $900 / 1800 \mathrm{MHz}$ EMF, then, 8 Gy x-ray, and a Wi-Fi+ X-ray group (Wi-Fi + RT group) 12 hours a day for 14 days exposed to $2400 \mathrm{MHz}$ EMF radiation, then, 8 Gy x-ray. The rats were exposed to the RF-EMF source with the condition identical for different groups. Our exposure setting is shown in Figure 1, also, was used in our recent studies for evaluating the liver tissue, its function, ${ }^{14}$ and also radioadaptive response ${ }^{15}$ in rats. The specific absorption rates (SAR) of the soft tissue of rats for mobile phone and Wi-Fi router were calculated earlier in our recent studies which were $5.57 \mathrm{~mW} / \mathrm{kg}$, and $91.99 \mathrm{~mW} /$ $\mathrm{kg}$, respectively. ${ }^{14,15}$ The 8 Gy x-ray was delivered by 200 $\mathrm{cGy} / \mathrm{min}$ dose rate, $115 \mathrm{~cm}$ SSD, $3.5 \mathrm{~cm}$ Depth, $983 \mathrm{MU}$, and $40 \times 40 \mathrm{~cm}$ field size using $6 \mathrm{MV}$ Elekta compact accelerator.

\section{BUN and $\mathrm{Cr}$ Measurements}

Sera were collected from $2 \mathrm{~mL}$ of rat blood, then stored at $-80^{\circ} \mathrm{C}$ until evaluation. The BUN, Cr were determined by
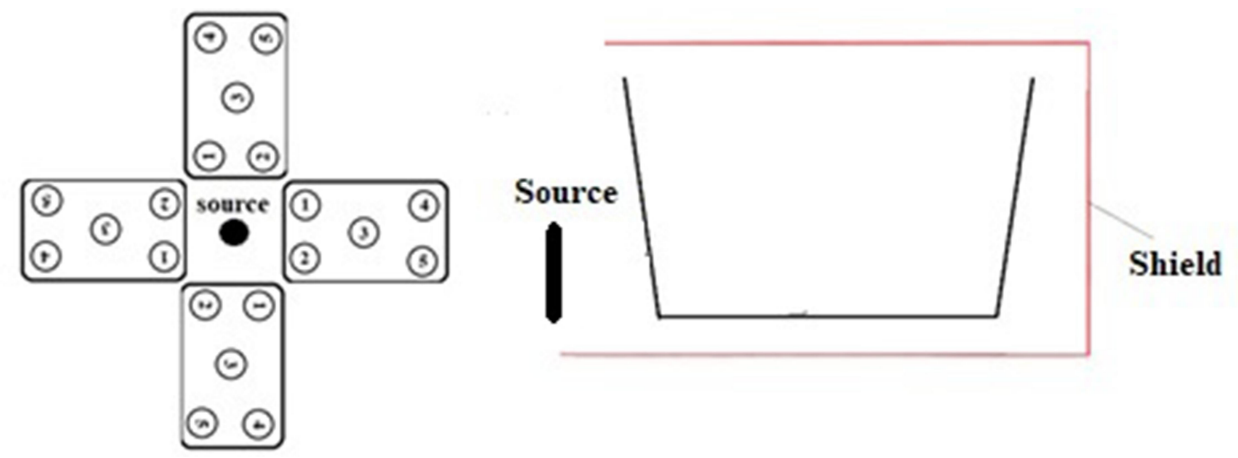

Figure I The design of RF-EMF irradiation design. The location of Plexiglas cage and the radiation source (mobile phone or Wi-Fi router) and lateral view of one cage were shown. 
a Cobas Mira autoanalyzer. The $\mathrm{Cr}$ were measured using colorimetric Kit (Pars Azmun, Iran). Briefly, $1000 \mu \mathrm{L}$ of reagent solution 1 was added to $50 \mu \mathrm{L}$ of sample and were incubated in $37^{\circ} \mathrm{c}$ for 5 minutes. Then, $250 \mu \mathrm{L}$ of reagent solution 2 was added, and after 1 and 2 minutes, the absorbance was measured. The BUN was measured using a colorimetric urea mono liquid Kit (biorexfars, Iran). Briefly, $1000 \mu \mathrm{L}$ of reagent $\mathrm{R} 1$ was added to $10 \mu \mathrm{L}$ of sample and after 30 and 40 seconds, the absorbance was measured.

\section{Histopathological Assessment}

The rats were sacrificed based on the ethical standards of international guidelines of the care of animals. Then, the right kidney was fixed in the buffered formalin $10 \%$. So after the process, the samples were stained with hematoxylin and eosin (H\&E). The damages were observed and listed in the coded form for blindness. The tubular tortuosity, tubular cyst formation, tubular vacuolization, tubular dilatation, tubular atrophy, interstitial inflammation, interstitial hemorrhage, interstitial edema, lymph vessel dilatation, vessel wall thickening, and inflammation of blood vessels were listed and analyzed.

\section{Statistical Analysis}

After testing normality by the Kolmogorov-Smirnov test, the BUN and $\mathrm{Cr}$ levels and $\mathrm{BUN} / \mathrm{Cr}$ ratio were compared by Kruskal-Wallis test in different groups. Also, the histopathological changes were compared by the Chi-square test, and the $p$ values lesser than 0.05 were considered significant.

\section{Results}

\section{$\mathrm{BUN}, \mathrm{Cr}$, and BUN/Cr Ratio}

The comparison of BUN, Cr, and BUN/Cr ratio among different groups was shown in Figures 2-4, respectively. As shown in these figures, 900/1800 and $2400 \mathrm{MHz}$ RFEMF exposures were compared with controls and RT groups separately. Also, each intervention was compared before and after receiving 8 Gy ionizing radiation.

\section{Histopathological Changes}

The histopathological changes of renal tissue due to $8 \mathrm{~Gy}$ dose of the x-ray with mobile and Wi-Fi interventions and their comparisons with positive and negative controls were analyzed 30 days after receiving the 8 Gy radiation dose. The changes were including tubular tortuosity, tubular cyst

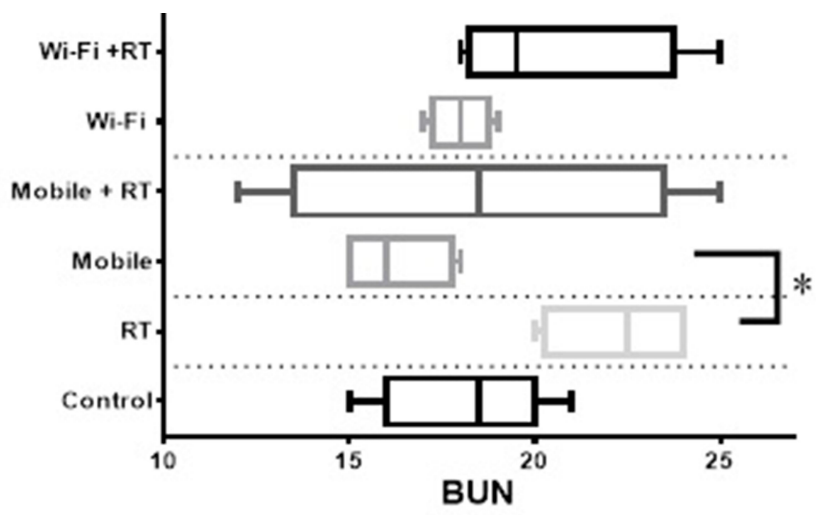

Figure 2 The blood urea nitrogen (BUN) levels of different study groups. The statistical analysis of results showed a significant difference between $8 \mathrm{~Gy}$ and mobile phone groups. *p value lower than 0.05 .

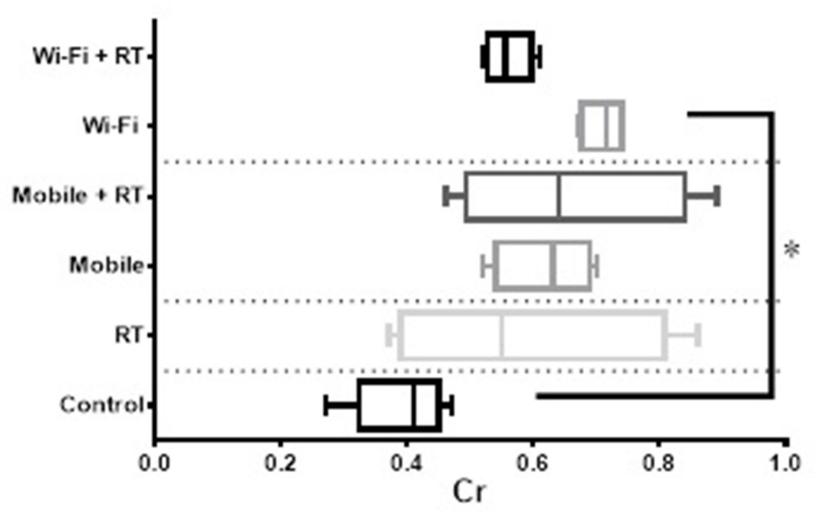

Figure 3 The $\mathrm{Cr}$ levels in different study groups. The statistical analysis of results showed a significant difference between control and $\mathrm{Wi}-\mathrm{Fi}$ groups. *p value lower than 0.05 .

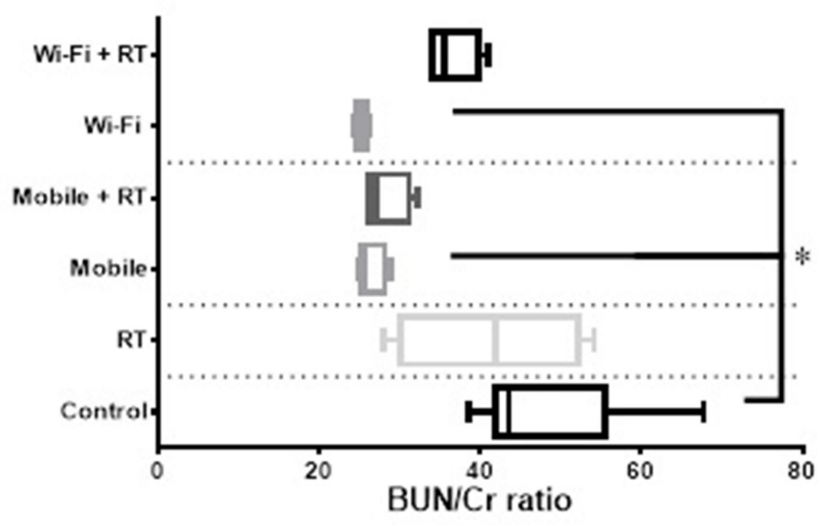

Figure 4 The BUN to $\mathrm{Cr}$ ratio levels in different study groups. The statistical analysis of results showed a significant difference between $\mathrm{Wi}$-Fi and mobile phone groups with control. *p value lower than 0.05 .

formation, tubular vacuolization, tubular dilatation, tubular atrophy, interstitial inflammation, interstitial hemorrhage, interstitial edema, lymph vessel dilatation, vessel wall 
thickening, and inflammation of blood vessels. The normal, hemorrhagic tissue, edema and inflammation, and tubular dilatation were presented in Figure 5. Also, the frequencies and percentages of different histopathological changes are analyzed in Table 1.

\section{Discussion}

The X-ray induced renal injuries in the presence of 900/ $1800 \mathrm{MHz}$ and $2400 \mathrm{MHz}$ EMF irradiations were studied. The serum levels of $\mathrm{BUN}, \mathrm{Cr}$, and $\mathrm{BUN} / \mathrm{Cr}$ ratio were compared, and the histopathological changes in the renal tissue were documented. In this section, we have discussed the effect of $900 / 1800 \mathrm{MHz}, 2400 \mathrm{MHz}$ radiation in the kidney, as one of the most radio-sensitive body organs, and their adaptive or synergistic effect has been hypothesized.

The normal range of BUN level in the rat reported being 8.5-22.7 in the previous study, ${ }^{16}$ which is in agreement with our results in the control group. Also, in mobile phone and Wi-Fi groups after receiving EMF, the difference of BUN and $\mathrm{Cr}$ levels with the control group were not statistically significant. However, both BUN and $\mathrm{Cr}$ levels raised non-significantly after receiving an 8Gy x-ray and, all of samples in RT groups were in borderline or higher than the measured range of the Stender et al study ${ }^{16}$ approving radiation-induced renal injury in these doses. Furthermore, pre-exposure to EMF before receiving $8 \mathrm{~Gy}$ $\mathrm{X}$-ray, did not change the BUN and $\mathrm{Cr}$ levels significantly but an extraordinary standard deviation of BUN and $\mathrm{Cr}$ in this group in addition to this fact that BUN in only $25 \%$ of samples (100\% without RT intervention) was in borderline or higher than normal range suggesting an adaptive response. This response could be due to alteration in the metabolism of free radicals ${ }^{17}$ in the kidney tissue by preexposure with acute electromagnetic field exposure which was noted in the study of Martínez-Sámano et $\mathrm{al}^{18}$ and Sefidbakht et al. ${ }^{19}$ This change in the antioxidant system and the ability of cells to overcome oxidative stress ${ }^{19}$ eventually could modulate the effects of consequent lethal doses of ionizing radiation known as adaptive response.

In our study, the BUN levels of control, Wi-Fi, RT, and Wi-Fi+RT groups were not significantly different. $\mathrm{Cr}$ levels in the Wi-Fi group were significantly higher than control, although this parameter in the $\mathrm{Wi}-\mathrm{Fi}+\mathrm{RT}$ group was not higher than control. Radiation-induced renal injuries could occur in the doses between 5 and 10 Gy. The doses higher than 10 Gy could induce gastrointestinal syndrome and fast death in which renal injuries have not the opportunity to appear. ${ }^{20}$ A literature search did not result in any study dealing with the radio-adaptive response of EMF in the kidney but yield the EMFinduced adaptation in other organs ${ }^{21}$ and adaptation provoked by ionizing radiation in kidneys were reported. ${ }^{22,23}$ The adaptive response could be due to an increase in oxidative damage induced by an adaptive dose of radiation. $^{24}$ Özorak A reported that exposure to mobile phones or Wi-Fi could lead to oxidative damage in the renal tissue of rats. ${ }^{11}$ Then, because there is a dose window for each frequency to provoke a radioadaptive response, ${ }^{15}$ it could be the source of our different results in 900/ $1800 \mathrm{MHz}$ and $2400 \mathrm{MHz}$ EMF interventions.

Both of Mobile and Wi-Fi group shown a decrease in $\mathrm{BUN} / \mathrm{Cr}$ ratio. The low $\mathrm{BUN} / \mathrm{Cr}$ ratio could be due to reduced



Figure $\mathbf{5}$ The histopathological evaluation of renal tissue before and after irradiations. (A) is normal tissue, (B) shows hemorrhage in the kidney, (C) shows edema and inflammation, and (D) shows tubular dilatation after irradiations. 
Table I The Comparison of Frequencies and Percentages of Different Histopathological Changes Due to 8Gy Dose of the x-Ray with Mobile and Wi-Fi Interventions and Their Comparisons with Positive and Negative Controls

\begin{tabular}{|c|c|c|c|c|c|c|c|c|c|c|c|}
\hline & & \multicolumn{2}{|c|}{ Control } & \multicolumn{2}{|c|}{ RT } & \multicolumn{2}{|c|}{ Mobile+RT } & \multicolumn{2}{|c|}{ Wi-Fi+RT } & \multirow[t]{2}{*}{ p-value for Mobile } & \multirow[t]{2}{*}{ p-value for Wi-Fi } \\
\hline & & $\mathbf{N}$ & $\%$ & $\mathbf{N}$ & $\%$ & $\mathbf{N}$ & $\%$ & $\mathbf{N}$ & $\%$ & & \\
\hline \multirow[t]{2}{*}{ Tubular tortuosity } & No & 8 & $100 \%$ & 6 & $75.0 \%$ & 6 & $75.0 \%$ & 4 & $50.0 \%$ & 0.301 & 0.069 \\
\hline & Yes & 0 & $0.0 \%$ & 2 & $25.0 \%$ & 2 & $25.0 \%$ & 4 & $50.0 \%$ & & \\
\hline \multirow[t]{2}{*}{ Tubular cyst formation } & No & 8 & $100 \%$ & 7 & $87.5 \%$ & 6 & $75.0 \%$ & 7 & $87.5 \%$ & 0.319 & 0.580 \\
\hline & Yes & 0 & $0.0 \%$ & I & $12.5 \%$ & 2 & $25.0 \%$ & 1 & $12.5 \%$ & & \\
\hline \multirow[t]{2}{*}{ Tubular vacuolization } & No & 8 & $100 \%$ & 6 & $75.0 \%$ & 4 & $50.0 \%$ & 6 & $75.0 \%$ & 0.069 & 0.301 \\
\hline & Yes & 0 & $0.0 \%$ & 2 & $25.0 \%$ & 4 & $50.0 \%$ & 2 & $25.0 \%$ & & \\
\hline \multirow[t]{2}{*}{ Tubular dilatation } & No & 8 & $100 \%$ & 7 & $87.5 \%$ & 7 & $87.5 \%$ & 7 & $87.5 \%$ & 0.580 & 0.580 \\
\hline & Yes & 0 & $0.0 \%$ & I & $12.5 \%$ & I & $12.5 \%$ & 1 & $12.5 \%$ & & \\
\hline \multirow[t]{2}{*}{ Tubular atrophy } & No & 8 & $100 \%$ & 8 & $100 \%$ & 6 & $75.0 \%$ & 5 & $62.5 \%$ & 0.113 & $0.032^{*}$ \\
\hline & Yes & 0 & $0.0 \%$ & 0 & $0.0 \%$ & 2 & $25.0 \%$ & 3 & $37.5 \%$ & & \\
\hline \multirow[t]{2}{*}{ Interstitial inflammation } & No & 8 & $100 \%$ & 7 & $87.5 \%$ & 7 & $87.5 \%$ & 7 & $87.5 \%$ & 0.580 & 0.580 \\
\hline & Yes & 0 & $0.0 \%$ & 1 & $12.5 \%$ & I & $12.5 \%$ & 1 & $12.5 \%$ & & \\
\hline \multirow[t]{2}{*}{ Interstitial hemorrhage } & No & 8 & $100 \%$ & 7 & $87.5 \%$ & 7 & $87.5 \%$ & 8 & $100 \%$ & 0.580 & 0.352 \\
\hline & Yes & 0 & $0.0 \%$ & I & $12.5 \%$ & I & $12.5 \%$ & 0 & $0.0 \%$ & & \\
\hline \multirow[t]{2}{*}{ Interstitial edema } & No & 8 & $100 \%$ & 8 & $100 \%$ & 7 & $87.5 \%$ & 6 & $75.0 \%$ & 0.352 & 0.113 \\
\hline & Yes & 0 & $0.0 \%$ & 0 & $0.0 \%$ & I & $12.5 \%$ & 2 & $25.0 \%$ & & \\
\hline \multirow[t]{2}{*}{ Lymph vessel dilatation } & No & 8 & $100 \%$ & 5 & $62.5 \%$ & 7 & $87.5 \%$ & 6 & $75.0 \%$ & 0.122 & 0.171 \\
\hline & Yes & 0 & $0.0 \%$ & 3 & $37.5 \%$ & 1 & $12.5 \%$ & 2 & $25.0 \%$ & & \\
\hline \multirow[t]{2}{*}{ Vessel wall thickening } & No & 8 & $100 \%$ & 8 & $100 \%$ & 8 & $100 \%$ & 4 & $50.0 \%$ & - & $0.008^{*}$ \\
\hline & Yes & 0 & $0.0 \%$ & 0 & $0.0 \%$ & 0 & $0.0 \%$ & 4 & $50.0 \%$ & & \\
\hline \multirow[t]{2}{*}{ Inflammation of blood vessels } & No & 8 & $100 \%$ & 8 & $100 \%$ & 8 & $100 \%$ & 7 & $87.5 \%$ & - & 0.352 \\
\hline & Yes & 0 & $0.0 \%$ & 0 & $0.0 \%$ & 0 & $0.0 \%$ & I & $12.5 \%$ & & \\
\hline
\end{tabular}

Note: *p value lower than 0.05

protein intake or liver disease, supernormal excretion of urea, increased creatinine production. ${ }^{25}$ We have irradiated the rats with EMF radiation for 14 days, and we will suggest the longterm evaluation of EMF-induced renal changes.

Radiation nephropathy could be one of the chronic outcomes of radiation exposure. ${ }^{26}$ The comparison of frequencies and percentages of different histopathological changes due to $8 \mathrm{~Gy}$ dose of the $\mathrm{x}$-ray with control, Mobile+RT, and Wi-Fi+RT interventions revealed that tubular atrophy and vessel wall thickening are associated with pre-exposure to Wi-Fi intervention. The serum level of $\mathrm{BUN}, \mathrm{Cr}$, and $\mathrm{BUN} / \mathrm{Cr}$ ratio is in agreement with this finding. Moreover, we have evaluated the histopathological changes after about four weeks of $\mathrm{x}$-ray irradiation, but $\mathrm{Ki}$ et al have evaluated the renal tissue 24 weeks after irradiation, and reported progressive glomerulosclerosis and tubulointerstitial fibrosis. ${ }^{26}$
In our study, we could conclude that exposure to 900/ $1800 \mathrm{MHz}, 2400 \mathrm{MHz}$ EMF could alter the function of the kidney but, pre-exposure to before mentioned dose of 900/ $1800 \mathrm{MHz}$ EMF could modulate the acute adverse effects of lethal x-ray dose and lead to better clearance of blood urea in this situation which addresses the radioadaptive response in the kidney. Although the exposure to this dose window of $2400 \mathrm{MHz}$ EMF did not show the adaptation response.

\section{Ethical Approval}

The ethical committee of Babol University of Medical Sciences, Babol, Iran, approved the study. The guidelines of Iran National Committee for Ethics in Biomedical Research for the welfare of the laboratory animals followed. 


\section{Funding}

This study was supported by the deputy of research and technology, Babol University of Medical Sciences, Babol, Iran.

\section{Disclosure}

The authors report no conflicts of interest for this work.

\section{References}

1. Allison RR. The electromagnetic spectrum: current and future applications in oncology. Future Oncol. 2013;9(5):657-667. doi:10.2217/ fon.13.12

2. Banik S, Bandyopadhyay S, Ganguly S. Bioeffects of microwave-a brief review. Bioresour Technol. 2003;87(2):155-159. doi:10.1016/ S0960-8524(02)00169-4

3. Aleksandrov SN, Galkovskaia KF, Gubareva AV. [The significance of the direct and indirect effect of ionizing radiation on radiation leukemia]. Vopr Onkol. 1970;16(11):80-85. Russian.

4. Cifra M, Fields JZ, Farhadi A. Electromagnetic cellular interactions. Prog Biophys Mol Biol. 2011;105(3):223-246. doi:10.1016/j. pbiomolbio.2010.07.003

5. Cui Y, Li R, Wang P. Novel dual-broadband planar antenna and its array for $2 \mathrm{G} / 3 \mathrm{G} / \mathrm{LTE}$ base stations. IEEE Trans Antennas Propag. 2012;61(3):1132-1139. doi:10.1109/TAP.2012.2229377

6. Vaughan-Nichols SJ. Gigabit Wi-Fi is on its way. Computer. 2010;43 (11):11-14. doi:10.1109/MC.2010.318

7. Miyakoshi J. Cellular and molecular responses to radio-frequency electromagnetic fields. Proc IEEE. 2013;101(6):1494-1502. doi:10.1109/JPROC.2013.2248111

8. Ragy MM. Effect of exposure and withdrawal of 900-MHzelectromagnetic waves on brain, kidney and liver oxidative stress and some biochemical parameters in male rats. Electromagn Biol Med. 2015;34(4):279-284. doi:10.3109/15368378.2014.906446

9. Gellrich J, Hakenberg OW, Oehlschlager S, Wirth MP. Manifestation, latency and management of late urological complications after curative radiotherapy for cervical carcinoma. Onkologie. 2003;26 (4):334-340.

10. Mercantepe T, Topcu A, Rakici S, Tumkaya L, Yilmaz A, Mercantepe $\mathrm{F}$. The radioprotective effect of $\mathrm{N}$-acetylcysteine against $\mathrm{x}$-radiation-induced renal injury in rats. Environ Sci Pollut Res. 2019;26(28):29085-29094. doi:10.1007/s11356-019-06110-0

11. Ozorak A, Naziroglu M, Celik O, et al. Wi-Fi (2.45 GHz)- and mobile phone (900 and $1800 \mathrm{MHz}$ )-induced risks on oxidative stress and elements in kidney and testis of rats during pregnancy and the development of offspring. Biol Trace Elem Res. 2013;156(1-3):221-229. doi:10.1007/s12011-013-9836-z

12. Jaggi JS, Seshan SV, McDevitt MR, Sgouros G, Hyjek E, Scheinberg DA. Mitigation of radiation nephropathy after internal $\alpha$ particle irradiation of kidneys. Int J Radiat Oncol Biol Phys. 2006;64 (5):1503-1512. doi:10.1016/j.ijrobp.2005.11.036

Research and Reports in Urology

\section{Publish your work in this journal}

Research and Reports in Urology is an international, peer-reviewed, open access journal publishing original research, reports, editorials, reviews and commentaries on all aspects of adult and pediatric urology in the clinic and laboratory including the following topics: Pathology, pathophysiology of urological disease; Investigation and
13. Roumeliotis S, Roumeliotis A, Dounousi E, Eleftheriadis T, Liakopoulos V. Dietary antioxidant supplements and uric acid in chronic kidney disease: a review. Nutrients. 2019;11(8):1911. doi:10.3390/nu11081911

14. Borzoueisileh S, Monfared AS, Ghorbani H, et al. The assessment of function, histopathological changes, and oxidative stress in liver tissue due to ionizing and non-ionizing radiations. Caspian J Intern Med. 2020;11(3):315-323.

15. Borzoueisileh S, Shabestani Monfared A, Mortazavi MJ, et al. Preexposure to radiofrequency electromagnetic fields and induction of radioadaptive response in rats irradiated with high doses of X-rays. J Biomed Phys Eng. 2020.

16. Stender RN, Engler WJ, Braun TM, Hankenson FC. Establishment of blood analyte intervals for laboratory mice and rats by use of a portable clinical analyzer. J Am Assoc Lab Anim Sci. 2007;46 (3):47-52.

17. Dasdag S, Akdag MZ. The link between radio frequencies emitted from wireless technologies and oxidative stress. $J$ Chem Neuroanat. 2016;75:85-93. doi:10.1016/j.jchemneu.2015.09.001

18. Martínez-Sámano J, Torres-Duran PV, Juárez-Oropeza MA, EliasVinas D, Verdugo-Díaz L. Effects of acute electromagnetic field exposure and movement restraint on antioxidant system in liver, heart, kidney and plasma of Wistar rats: a preliminary report. Int J Radiat Biol. 2010;86(12):1088-1094.

19. Sefidbakht Y, Moosavi-Movahedi AA, Hosseinkhani S, et al. Effects of $940 \mathrm{MHz}$ EMF on bioluminescence and oxidative response of stable luciferase producing HEK cells. Photochem Photobiol Sci. 2014;13(7):1082-1092. doi:10.1039/C3PP50451D

20. Baradaran-Ghahfarokhi M. Radiation-induced kidney injury. J Renal Inj Prev. 2012;1(2):49-50.

21. Tarantino P, Lanubile R, Lacalandra G, Abbro L, Dini L. Postcontinuous whole body exposure of rabbits to $650 \mathrm{MHz}$ electromagnetic fields: effects on liver, spleen, and brain. Radiat Environ Biophys. 2005;44(1):51-59. doi:10.1007/s00411-005-0274-y

22. Pathak CM, Avti PK, Kumar S, Khanduja KL, Sharma SC. Whole body exposure to low-dose gamma radiation promotes kidney antioxidant status in Balb/c mice. J Radiat Res. 2007;48(2):113-120. doi: $10.1269 /$ jrr.06063

23. Mortazavi S, Mortazavi G, Haghani M, Mortazavi S. Oxidative stress, a bridge that links radioadaptive responses induced by ionizing radiation to those induced by non-ionizing radiation. Reactive Oxygen Species. 2016;1(3):199-206.

24. Sisakht M, Darabian M, Mahmoodzadeh A, et al. The role of radiation induced oxidative stress as a regulator of radio-adaptive responses. Int J Radiat Biol. 2020;1-16.

25. Clark VL, Kruse JA. Clinical methods: the history, physical, and laboratory examinations. JAMA. 1990;264(21):2808-2809. doi:10.1001/jama.1990.03450210108045

26. Ki Y, Kim W, Kim YH, et al. Effect of coenzyme Q10 on radiation nephropathy in rats. $J$ Korean Med Sci. 2017;32(5):757-763. doi:10.3346/jkms.2017.32.5.757 treatment of urological disease; Pharmacology of drugs used for the treatment of urological disease. The manuscript management system is completely online and includes a very quick and fair peer-review system, which is all easy to use. Visit http://www.dovepress.com/ testimonials.php to read real quotes from published authors. 